吉戒男, 崔绍朋, 邓怀庆, 李春旺, 肖能文.生物多样性保护优先区抽样调查策略研究一一武陵山地区为例.生态学报, 2021,41(24):9604-9612. Ji S N, Cui S P, Deng H Q, Li C W, Xiao N W.Sampling survey strategy in biodiversity conservation priority areas: the case of Wuling Mountains. Acta Ecologica Sinica, 2021,41(24) : 9604-9612.

\title{
生物多样性保护优先区抽样调查策略研究
}

以武陵山地区为例

\author{
吉晟男 ${ }^{1}$, 崔绍朋 ${ }^{2 *}$, 邓怀庆 ${ }^{3}$, 李春旺 ${ }^{4,5}$, 肖能文 ${ }^{1}$ \\ 1 中国环境科学研究院 国家环境保护区域生态过程与功能评估重点实验室, 北京 100012 \\ 2 山西农业大学 林学院,晋中 030801 \\ 3 贵州师范大学 生命科学学院,贵阳 550001 \\ 4 中国科学院动物研究所 动物生态与保护生物学院重点实验室,北京 100101 \\ 5 中国科学院大学, 北京 100049
}

摘要:生物多样性保护优先区是我国为加强生物多样性保护和监管划定的重要区域,目前部分优先区已陆续开展生物本底资料 的调查评估工作, 但受限于经费、时间等条件, 对区内所有县域或网格全覆盖式科考, 既不现实也无必要, 因而区域尺度的抽样 设计是一个亟需解决的关键问题。以武陵山生物多样性保护优先区为例, 结合层次聚类和系统抽样方法, 同时考虑历史调查资 料的系统完整程度和空间保护属性,提出了一个科学可行的抽样方案。首先将研究区域内的所有县域聚为 5 类,每类挑选出 2 个重点县域,共获得 6 个历史上进行过系统科学考察的县域和 4 个本底资料相对缺乏的县域,进而挑选出 76 个重点调查网格 $(10 \mathrm{~km} \times 10 \mathrm{~km})$, 其中生物多样性富集网格 36 个,保护区外的人类干扰网格 40 个,抽样比例为 $11.09 \%$, 每个网格平均调查经 费为 2.52 万元。该抽样策略区分了调查层次并突出重点区域,使调查和评估更有针对性,进一步完善了保护优先区基础调查 系统,也强化了项目管理能力, 对其他保护优先区项目开展具有一定参考价值。

关键词:生物多样性保护优先区;基础调查;抽样策略;武陵山

\section{Sampling survey strategy in biodiversity conservation priority areas : the case of Wuling Mountains}

\footnotetext{
JI Shengnan ${ }^{1}$, CUI Shaopeng ${ }^{2, *}$, DENG Huaiqing ${ }^{3}$, LI Chunwang ${ }^{4,5}$, XIAO Nengwen ${ }^{1}$

1 State Environmental Protection Key Laboratory of Regional Ecological Processes and Functions Assessment, Chinese Research Academy of Environmental Sciences, Beijing 100012, China

2 College of Forestry, Shanxi Agricultural University, Jinzhong 030801, China

3 School of Life Sciences, Guizhou Normal University, Guiyang 550001, China

4 Key Laboratory of Animal Ecology and Conservation Biology, Institute of Zoology, Chinese Academy of Sciences, Beijing 100101, China

5 University of Chinese Academy of Sciences, Beijing 100049, China
}

\begin{abstract}
The biodiversity conservation priority areas are the important areas designated by China to strengthen biodiversity protection and supervision. At present, some priority areas have successively carried out investigation and evaluation of biodiversity background data. However, the full coverage of all counties or grids in the survey area is neither realistic nor necessary due to the limited funding, time and other conditions. Given that, the sampling design at the regional scale becomes a key issue that needs to be resolved. Taking the biodiversity conservation priority area in the Wuling Mountains as
\end{abstract}

基金项目:生态环境部生物多样性调查评估项目(2019HJ2096001006); 山西省高等学校科技创新项目(2021L0147)

收稿日期:2021-03-25; 采用日期:2021-08-14

*通讯作者 Corresponding author.E-mail: shaopengcui@126.com 
an example, we proposed a scientific and feasible sampling plan by combining hierarchical clustering and systematic sampling. Simultaneously, the systematic integrity of historical survey data and spatial attribute for conservation was also considered. We firstly grouped all counties in the study area into five categories, then selected 2 key counties for each category. According to the above principles, we obtained 6 counties that once investigated scientifically and 4 counties with a relative lack of survey data. Finally, 76 key survey grids ( $10 \mathrm{~km} \times 10 \mathrm{~km}$ ) were selected, including 36 biodiversity enrichment grids and 40 human disturbance grids outside the protected areas, with a sampling ratio of $11.09 \%$. The average survey funding for each grid was 25,200 RMB. By the stratified sampling and emphasizing on key areas, the surveys and assessments become more target-oriented. The sampling strategy improved the basic survey system of conservation priority areas, strengthened the capacity of project management, and provided a paradigm for other conservation priority areas.

Key Words : biodiversity conservation priority areas; basic survey; sampling strategy ; Wuling Mountains

我国是世界上生物多样性最丰富的国家之一, 目前已记录物种 110231 种, 其中高等植物 37700 余种, 居 世界第三位; 脊椎动物 4300 多种 (海洋鱼类除外), 近 $37 \%$ 的物种为中国特有种 ${ }^{[1-2]}$ 。我国也是生物多样性受 威胁最严重的国家之一,受威胁物种比例达 $21.4 \%^{[1]}$ 。

面对生物多样性保护严峻形势, 我国各级政府和相关部门采取了积极的应对措施 ${ }^{[3-4]}$ 。2010 年,国家常 务会议第 126 次会议审议并原则通过了《中国生物多样性保护战略与行动计划 (2011-2030 年)》, 将生物多 样性本底调查与观测作为主要任务和优先行动 ${ }^{[5-6]}$ 。2015 年, 为贯彻落实该行动计划, 加强生物多样性重点 区域保护与监管, 环境保护部 (现生态环境部) 核定生物多样性保护优先区域边界, 确定了 35 个中国生物多 样性保护优先区 ( 以下简称保护优先区), 以推动实现国家生态保护工程战略。2016 年, 保护优先区生物多样 性本底调查与评估示范项目启动, 在云南、四川、湖北、陕西、北京等地区选择了部分县域作为试点调查, 为期 二年。2019 年,武陵山、太行山、横断山南段等保护优先区的调查工作全面展开, 以 $10 \mathrm{~km} \times 10 \mathrm{~km}$ 面积的网 格 (以下简称网格) 为调查单元, 旨在摸清本底、掌握变化、明确威胁和评估保护成效, 从而提出针对性保护对 策建议,有效推动生物多样性保护和管理工作。

保护优先区面积大且涉及县域数量多, 如武陵山生物多样性保护优先区 ( 以下简称武陵山区) 总面积 $68549 \mathrm{~km}^{2}$, 涉及 5 个省 (直辖市) 的 44 个县域(图 1), 重点网格 686 个。由于项目经费、调查强度、工作时间 等有限, 对每个县域和网格进行全面调查并不现实也无必要。因而, 为使调查和评估更有针对性, 项目前期对 抽样技术的顶层设计至关重要 ${ }^{[7-8]}$ 。一般来说, 抽样方法主要包括简单随机抽样、分层抽样、系统抽样和聚类 抽样四种, 实践中往往不同抽样方法分阶段结合使用 ${ }^{[7,9]}$ 。文献回顾发现, 目前并无针对保护优先区抽样策 略的相关研究报道,这势必会影响我国生物多样性保护工作的实施。

本研究以武陵山区为研究对象, 在项目正式开始调查前, 对武陵山区生物多样性现状进行预评, 旨在提出 一套科学可行的抽样策略, 进一步完善保护优先区生物多样性基础调查系统, 强化项目管理能力。本研究首 先甄选代表性指标, 采用层次聚类方法对武陵山区县域进行分类, 结合当地可供比较的本底资料的系统性和 完整性, 挑选出重点调查县域。针对每个调查县域, 将网格与保护区数据图层叠加, 挑选出保护区内的网格作 为生物多样性富集网格, 依据系统抽样原则等间隔抽取保护区外的网格作为人类干扰网格,两类网格共同组 成重点调查网格,便于后续数据对比和分析。

\section{1 研究区域概况}

武陵山区位于湖北、湖南、重庆、四川和贵州五省交界处 $\left(106^{\circ} 56^{\prime}-111^{\circ} 49^{\prime} \mathrm{E}, 27^{\circ} 10^{\prime}-31^{\circ} 28^{\prime} \mathrm{N}\right.$, 图 1), 属 于云贵高原的东部延伸地带, 是我国西南高山高原向东南低山丘陵及长江中下游平原的过渡地区, 由一系列 北东向平行禇皱山地组成。平均海拔约 $1000 \mathrm{~m}$, 主峰为贵州东北部的梵净山最高峰风凰山, 海拔 $2572 \mathrm{~m}$ 。武 陵山区具有明显的中亚热带季风山地湿润气候特征, 属于亚热带向暖温带过渡类型, 热量充足, 降水充沛, 是 
乌江、沅江、澧水的分水岭, 水系发育成熟 ${ }^{[10]}$ 。立体型的地貌结构和气候布局, 为动植物的生存提供了丰富多

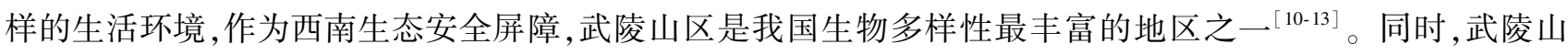
区位于我国西南山地边缘, 也是全球重要的生物多样性热点地区 ${ }^{[14]}$ 。在古地质地理背景下, 本区受第四纪冰 川寒流的影响较小, 是众多生物类群的南北迁移通道及古老子遗物种的庇护所 ${ }^{[15]}$ 。

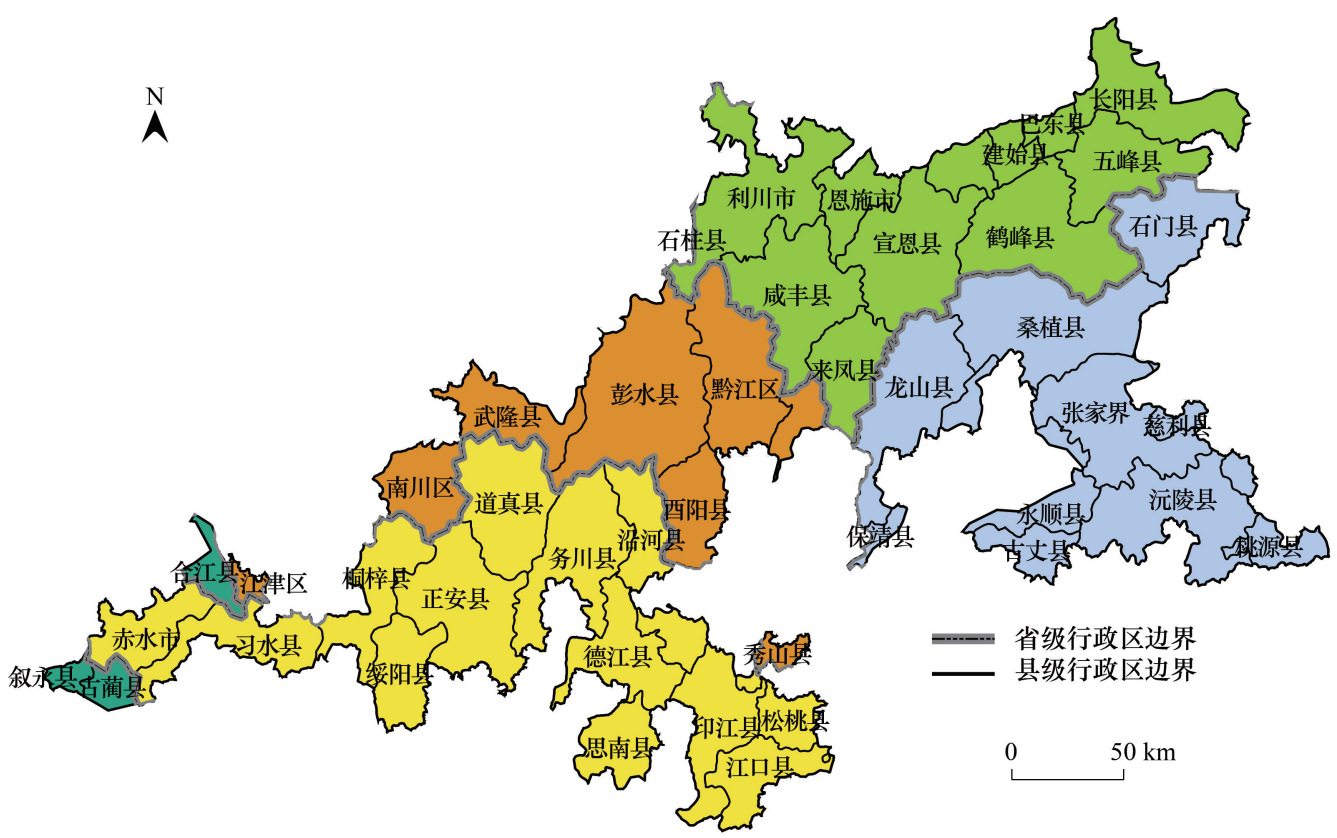

图 1 武陵山生物多样性保护优先区行政区划

Fig.1 The administrative division in Wuling Mountains conservation priority area

武陵山区生物多样性研究报道较多, 并且大部分为基础调查研究。其中大范围系统性的生物多样性调查 工作主要有两次。第一次在 1988-1990 年间,中国科学院组织来自 13 个研究所的 500 余位科学工作者对武 陵山区进行了生物资源的全面调查和评价, 并且作为 “七五”重大项目研究成果, 出版了《西南武陵山地区动 物资源和评价》《西南武陵山地区无脊椎动物》《西南武陵山地区昆虫》《武陵山地区维管植物检索表》等多本 专著 ${ }^{[10-13]}$ 。2014 年 7 月, 国家科技基础性工作专项 “武陵山生物多样性综合考察” 项目启动, 主要对武陵山区 域的动植物多样性开展连续 5 年的全面野外考察, 并对区域内的资源现状进行评估, 但目前尚未有结果发布。

\section{2 研究方法}

\section{1 数据来源与处理}

为保证数据质量和可比性, 同时由于前期工作时间有限, 本研究并没有收集现有的生物多样性和社会经 济零散资料,而是严谨地选取一些被广泛认可的代表性数据库, 以建立统一的分析框架。这些数据库都执行 了严格的数据收集工作,并对信息源进行了质量控制,适合对项目区域现状进行初步判断。

动物方面, 选择 Jenkins 等在 2013 年建立的哺乳类、鸟类和两栖类物种多样性分布数据库 ${ }^{[16]}$, 分辨率 10 $\mathrm{km}$, 同时又下载了 Roll 等在 2017 年建立的爬行动物矢量分布数据集 ${ }^{[17]}$, 最终形成陆生脊椎动物数据库。植 物方面, 选择 $\mathrm{Xu}$ 等在 2016 年建立的中国维管束植物丰富度县级分布数据集 ${ }^{[18]}$, 该成果能很好地满足项目需 求。生态系统方面,下载中国 1:100 万植被类型空间分布数据,此图集是研究国家自然资源和地理特征必不 可少的科学资料和重要依据 ${ }^{[19-20]}$ 。人类活动强度方面, 本研究选择 Venter 等在 2016 年建立的人类足迹数据 库 ${ }^{[21]}$,分辨率 $1 \mathrm{~km}$, 该数据库整合了人口居住地、土地利用类型、道路网络、基础设施建设等 8 个基本图层,可 以代表人类活动的总体强度。本文所用行政边界矢量数据来自国家基础地理信息中心 1:100 万全国基础地 
理数据库。

依据所获数据, 最终确定五个抽样指标: 动物丰富度、植物丰富度、物种受威胁程度、生态系统多样性、人 类活动强度 $($ 表 1$)$ 。

表 1 武陵山生物多样性保护优先区聚类抽样指标

Table 1 Cluster sampling indicators in Wuling Mountains conservation priority area

\begin{tabular}{llllc}
\hline $\begin{array}{l}\text { 项目目标 } \\
\text { Project objectives }\end{array}$ & $\begin{array}{l}\text { 评估层 } \\
\text { Evaluation layer }\end{array}$ & $\begin{array}{l}\text { 指标 } \\
\text { Indicator }\end{array}$ & $\begin{array}{l}\text { 计算 } \\
\text { Calculation }\end{array}$ & $\begin{array}{c}\text { 资料来源 } \\
\text { Source }\end{array}$ \\
\hline 生物多样性调查 & 物种 & 动物丰富度 & 陆生脊椎动物物种丰富度 & {$[16-17]$} \\
Biodiversity survey & & 植物丰富度 & 维管束植物物种丰富度 & {$[18]$} \\
& & 物种受威胁程度 & IUCN 红色名录列为 VU、EN 和 & {$[$ CR 级的脊椎动物种类数 } \\
& 生态系统 & 生境多样性 & 包含的植被亚类数目 & {$[16]$} \\
生物多样性评估 & 人类活动 & 人类活动强度 & 人类足迹指数均值 & {$[21]$} \\
Biodiversity assessment & & & & {$[20]$} \\
\hline
\end{tabular}

IUCN : 世界自然保护联盟 Internationl union for conservation of nature; VU:易危 Vulnerable;EN : 濒危 Endangered;CR:极危 Critically endangered

\section{2 层次聚类与县域抽样}

层次聚类又称树聚类, 是实际应用最为广泛的聚类算法之一 ${ }^{[22]}$ 。基于数据联接规则,该方法反复将数据 进行分裂和聚合, 以形成一个层次序列的聚类问题解,算法快速直观,能有效进行数据划分或分组处理 ${ }^{[22-25]}$ 。

对于所获数据,利用 ArcGIS 9.3 进行投影变换、裁剪、空间叠加和提取,分别得到武陵山区不同指标图层, 计算平均值并赋值给 44 个不同县域。使用 SAS 9.1 执行层次聚类统计分析,依据半偏决定系数 ( semi-partial $R$-squared, SPRSQ) 统计量, 并结合人类活动强度和生物多样性丰富程度, 确定合适分类数量。

依据武陵山区历史综合科学考察资料 ${ }^{[10-13]}$ 确定历史调查地点, 即生物多样性本底资料系统且完整地区。 为了在项目后期深人对比分析生物多样性的历史与现状,重点考虑这些地区, 同时衡量县域抽样空间分布的 均匀性和经费成本,对所有县域进行层次聚类后,每类挑选 2 个作为重点调查县域。

\section{3 系统抽样与网格抽样}

系统抽样又称等距抽样,一般采用简单随机抽样抽取第一个样本单元, 然后依据一定的抽样距离抽取其 他样本单元。该方法简单机械, 能很大程度避免主观选择偏好的影响, 是常见的生物多样性调查项目抽样 方法 $^{[7,9,26]}$ 。

针对挑选出的重点调查县域, 为了便于在项目调查完成后对比分析保护现状与成效,依据自然保护区分 布情况, 将县域内的网格分为两类,即生物多样性富集网格和人类干扰网格。利用 Arc GIS 软件将网格图层 与自然保护区图层进行空间叠加,挑选出有保护区分布的网格作为生物多样性富集类型网格。武陵山区自然 保护区数据源自生态环境部 2017 年发布的《全国自然保护区名录》。依据系统抽样原则, 间隔 1 - 2 个网格进 一步抽取位于保护区外的网格作为人类干扰网格。确保两类网格数量近似相等,最终挑选出的所有网格作为 项目重点调查网格。根据武陵山区项目总体预算,计算分析植物、兽类、鸟类、两爬、昆虫、真菌等类群的单元 网格经费分配情况。

\section{3 结果与分析}

\section{1 县域聚类}

对 44 个县域进行层次聚类分析结果表明,武陵山区应分为 5 类区域(图 2), 每类可简要概括为:第 I 类, 人类活动强度剧烈, 植物丰富度较低, 但动物丰富度高; 第 II 类, 人类活动强度较高, 动植物丰富度也较高; 第 III类, 人类活动强度中等, 动植物丰富度较高, 但受威胁物种种类少; 第 $\mathrm{I}$ 类, 人类活动强度中等, 植物丰富度 高,但动物丰富度低;第 $\mathrm{V}$ 类, 人类活动强度低,受威胁物种种类多。 


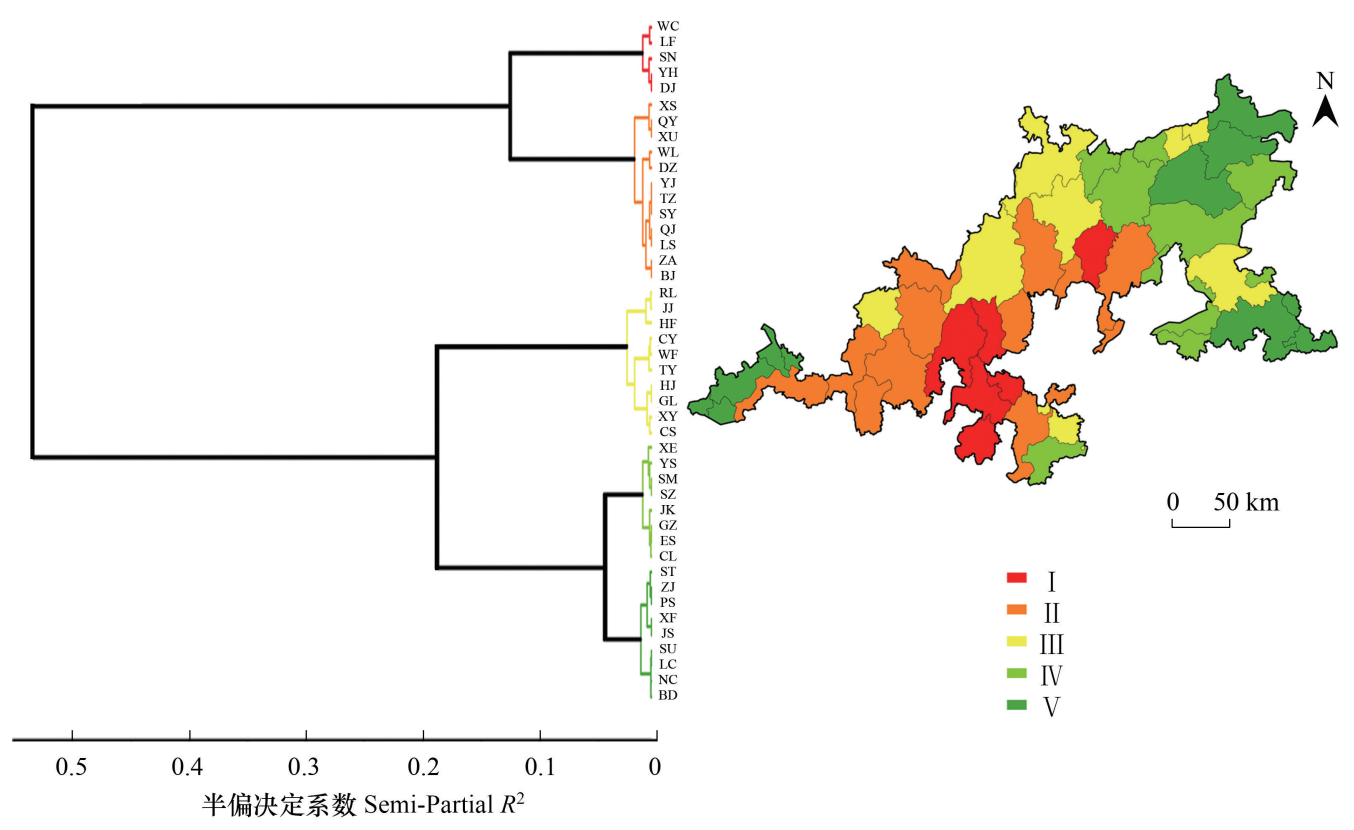

图 2 武陵山生物多样性保护优先区县域层次聚类

Fig.2 Hierarchical clustering of counties in Wuling Mountains conservation priority area

$\mathrm{WC}$ : 务川县, $\mathrm{LF}$ : 来风县, $\mathrm{SN}$ : 思南县, $\mathrm{YH}$ : 沿河县, $\mathrm{DJ}$ : 德江县, $\mathrm{XS}$ : 秀山县, $\mathrm{QY}$ : 西阳县, $\mathrm{XU}$ : 习水县, $\mathrm{WL}$ : 武隆县, $\mathrm{DZ}$ : 道真县, $\mathrm{YJ}$ : 印江 县, $\mathrm{TZ}$ : 桐梓县, $\mathrm{SY}$ : 绥阳县, $\mathrm{QJ}$ : 黔江区, $\mathrm{LS}$ : 龙山县, $\mathrm{ZA}$ : 正安县, $\mathrm{BJ}$ : 保靖县, $\mathrm{RL}$ : 沅陵县, JJ: 江津区, HF: 鹤峰县, CY: 长阳县, WF: 五 峰县, $\mathrm{TY}$ : 桃源县, $\mathrm{HJ}$ : 合江县, $\mathrm{GL}$ : 古萄县, $\mathrm{XY}$ : 叙永县, $\mathrm{CS}$ : 赤水市, $\mathrm{XE}$ : 宣恩县, $\mathrm{YS}$ : 永顺县, $\mathrm{SM}$ : 石门县, $\mathrm{SZ}$ : 桑植县, JK: 江口县, $\mathrm{GZ}$ : 古丈县, $\mathrm{ES}$ : 恩施市, $\mathrm{CL}$ : 慈利县, $\mathrm{ST}$ : 松桃县, $\mathrm{ZJ}$ : 张家界, PS: 彭水县, $\mathrm{XF}$ : 咸丰县, JS: 建始县, $\mathrm{SU}$ : 石柱县, $\mathrm{LC}:$ 利川市, $\mathrm{NC}$ : 南川区, BD: 巴东县

\section{2 重点县域挑选}

文献回顾发现,历史上武陵山区综合科学考察地点主要分为两部分: 南部主要位于江口县梵净山地区, 北 部主要位于桑植县八大公山周围及张家界地区(图 3)。综合考虑层次聚类结果 (图 2) 和时间维度上的可对 比性,在上述范围内本文挑选了 6 个县域,同时在系统性本底资料相对缺乏区域选择了 4 个县域,最终挑选出 10 个重点调查县域, 分属 5 类区域: 务川县 \& 来凤县 (第 I 类)、习水县 \& 印江县 (第 II 类)、南川区 \& 张家界 市辖区 (第 III 类)、桑植县 \& 江口县 (第 $\mathrm{I}$ 类)、鹤峰县 \& 赤水县 (第 $\mathrm{V}$ 类)。

\section{3 重点调查网格}

依据空间叠加识别和系统抽样, 本研究共获得 76 个重点调查网格,其中生物多样性富集网格 36 个,保护 区外的人类干扰网格 40 个,两类网格数量比例接近 1:1, 抽样面积占武陵山区总面积的 $11.09 \%$ 。以湖南地区 鹤峰县为例 (图 4), 该地区共包括 9 个重点调查网格,其中位于有木林子国家级自然保护区分布的有 5 个, 其 余 4 个位于保护区外,间隔 $1-2$ 个网格,均匀分布在鹤峰县南部。

经费分配上,植物、兽类、鸟类、两爬、昆虫、真菌六大类群的总经费为 1151 万元 (表 2), 对于依据本研究 抽取的 76 个网格, 每个网格所有类群总经费 15.15 万元, 每个类群平均经费为 2.52 万元。不同类群的网格平 均经费并不相同, 其中植物最高, 为 4.68 万元, 其次兽类为 2.91 万元, 鸟类、两爬和昆虫相等, 均为 1.95 万元, 真菌平均经费最低,为 1.71 万元。

\section{4 讨论与结论}

\section{1 讨论}

为了使样本能够更好地代表总体, 抽样设计应尽可能避免盲目和主观随意 ${ }^{[9,27-30]}$ 。不同于常规普查项 目,在保护优先区开展的生物多样性项目应调查与评估并重,物种或类群受威胁状态评估亦是重要目标。如 


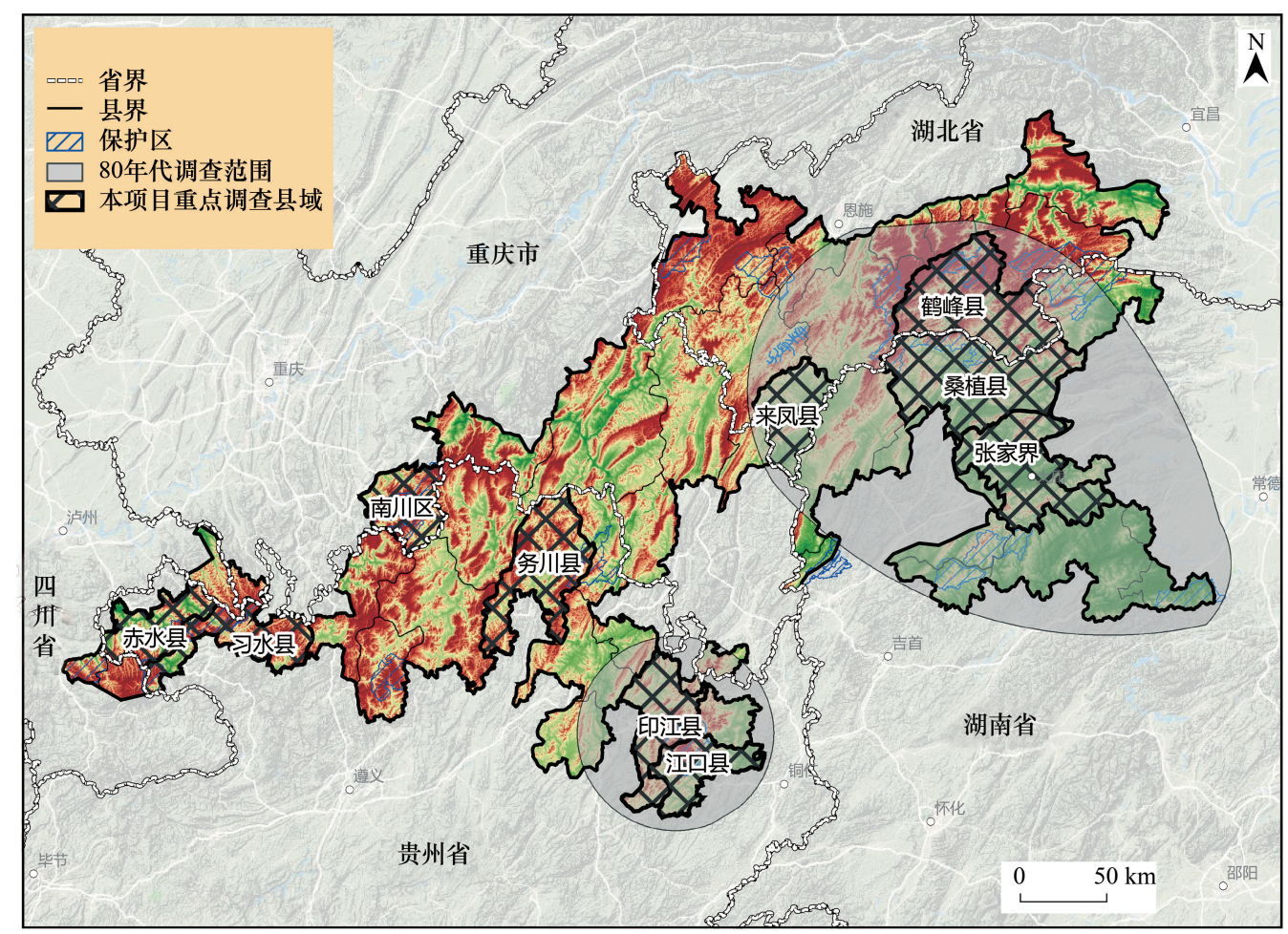

图 3 武陵山生物多样性保护优先区重点调查县域分布

Fig.3 Key research counties in Wuling Mountains conservation priority area

果仅在数据获得性强的生物多样性丰富地区进行调查, 无疑会大大削弱调查数据的有效评估能力。因此, 保 护优先区抽样策略需兼顾科学性和代表性原则, 区分调查层次并突出重点区域,同时应特别注意数据的可对 比性, 比如时间维度上与历史数据的对比, 空间维度上保护区内外生物多样性本底的对比, 这将直接关系到项 目结果的客观与可靠程度。本研究提出聚类抽样和系统抽样相结合的抽样策略, 同时考虑了历史调查资料的 系统完整程度和空间保护属性,将是否进行过系统的科学考察以及是否在保护区内作为分类和挑选标准,有 利于在调查完成后对比分析生物多样性时空变化和保护成效,更有助于制定“一类一策” 的管理措施 ${ }^{[29]}$, 提 高项目针对性和有效性。

表 2 武陵山生物多样性保护优先区主要类群项目经费分配/万元

Table 2 Project fund allocation for main biological groups in Wuling Mountains conservation priority area/ten thousand RMB

\begin{tabular}{lcc||lrr}
\hline $\begin{array}{l}\text { 类群 } \\
\text { Taxa }\end{array}$ & $\begin{array}{c}\text { 经费总额 } \\
\text { Total funding }\end{array}$ & $\begin{array}{c}\text { 网格平均经费 } \\
\text { Average cost of grid }\end{array}$ & $\begin{array}{l}\text { 类群 } \\
\text { Taxa }\end{array}$ & $\begin{array}{c}\text { 经费总额 } \\
\text { Total funding }\end{array}$ & $\begin{array}{c}\text { 网格平均经费 } \\
\text { Average cost of grid }\end{array}$ \\
\cline { 1 - 2 } 植物 Vascular plant & 356 & 4.68 & 昆虫 Insect & 148 & 1.95 \\
兽类 Mammal & 221 & 2.91 & 真菌 Fungus & 130 & 1.71 \\
鸟类 Bird & 148 & 1.95 & 总计 Total & 1151 & 15.15 \\
两爬 Amphibious \& Reptile & 148 & 1.95 & & & \\
\hline
\end{tabular}

本研究最终挑选出 76 个调查网格,抽样面积比例为 $11.09 \%$,需要注意的是,本研究的抽样结果是作为武 陵山区项目必须完成的最低工作量, 属于项目质控的必然要求, 调查团队可根据调查对象、工作基础、区域特 点等进行灵活补充, 可依据实际情况提高抽样比例。此外, 本研究抽样比例也受限于项目经费和调查强度。 以兽类为例, 每个调查网格的平均经费为 2.91 万元, 调查要求每个网格中样线数量不少于 2 条且样线总长度 不少于 $6 \mathrm{~km}$, 布设红外相机不少于 5 台,布设调查啮齿类等小型兽类的样方 $(100 \mathrm{~m} \times 100 \mathrm{~m})$ 不少于 2 个, 同 时一般应在春夏或秋冬季各进行 1 次调查。对于一个 $10 \mathrm{~km} \times 10 \mathrm{~km}$ 网格来说,调查经费显然并不宽松。 


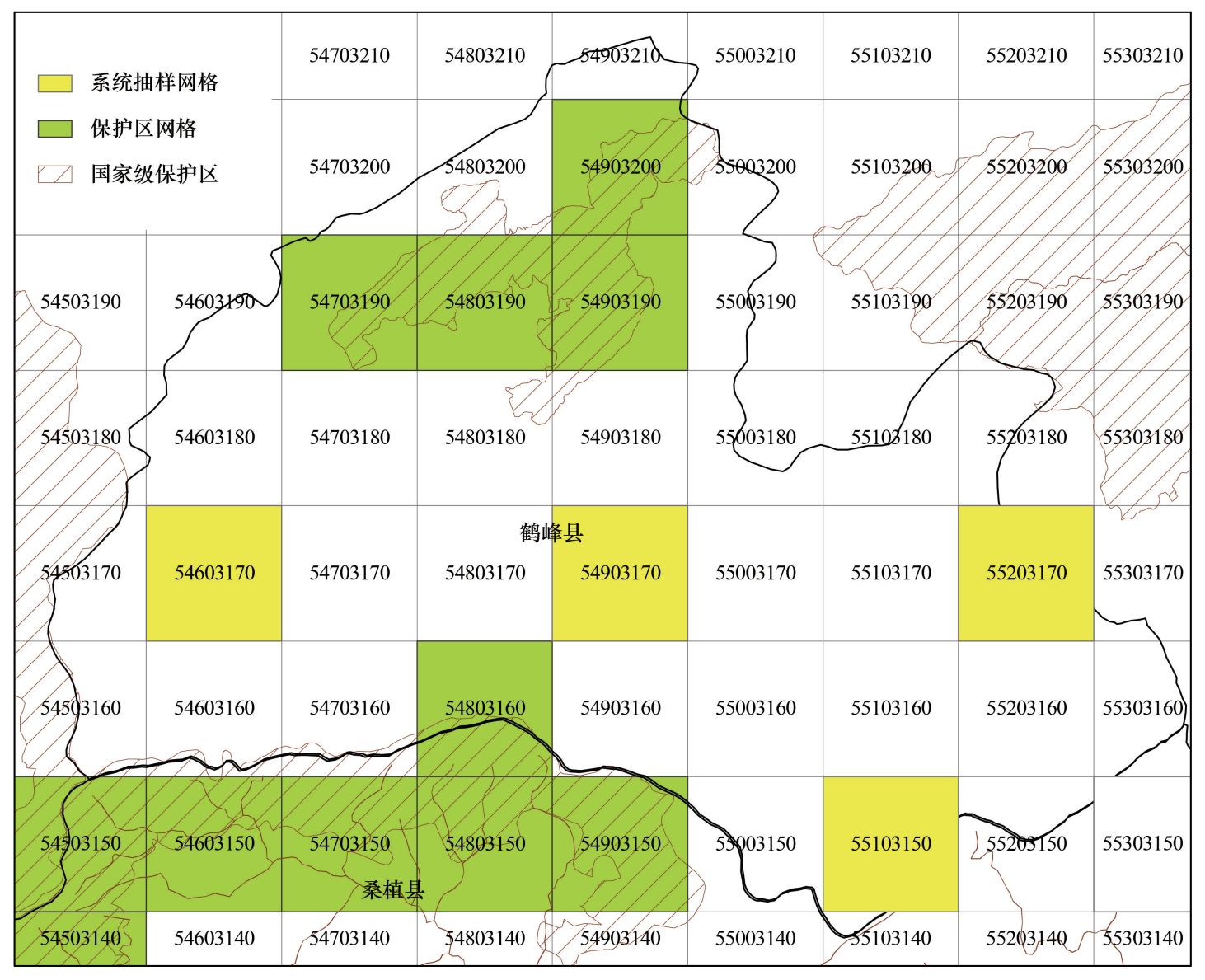

$10 \mathrm{~km}$

图 4 武陵山生物多样性保护优先区鹤峰县重点调查网格

Fig.4 Key research grids in Hefeng County of Wuling Mountains conservation priority area

本研究并未按照生境类型分层抽样 ${ }^{[7,27]}$, 主要有两个原因:一方面, 抽样必须要考虑空间尺度问题,武陵 山区生境复杂, 尽管对于抽样单元大小和形状目前尚有争论 ${ }^{[7,31]}$, 但项目要求以 $10 \mathrm{~km} \times 10 \mathrm{~km}$ 网格为调查单 元,所有调查数据也需按照网格编号使用手机 APP 即时上传至云端, 但每个 $100 \mathrm{~km}^{2}$ 面积的网格包含了多种 不同生境类型,基本很难找出仅包含一种生境的网格,所以无法按照生境类型区分网格。另一方面,不同类群 对生境类型划分要求是不同的,植物调查要尽可能细化,兽类、鸟类等类群比较粗放,很难统一。在网格中布 设样线、样方、样点等进行实地调查时,即在微生境尺度, 必须要考虑生境问题, 应兼顾不同植被类型和海拔

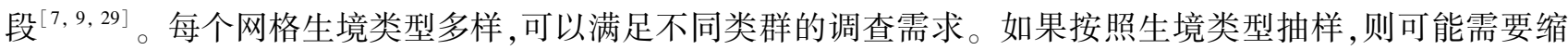
小调查单元面积, 比如缩小至 $2 \mathrm{~km} \times 2 \mathrm{~km}$,数据汇总提交格式也要相应调整。

目前,武陵山、京津冀太行山、横断山南段等保护优先区调查对象均分为高等植物、兽类、鸟类、两爬、昆 虫、真菌等, 不同类群具有不同的特性和空间变异性, 本文提出的抽样策略对于类群特异性抽样设计具有一定 的参考价值。与简单随机抽样相比, 分层抽样可以更好的反映目标区域特征, 进而减少空间误差 ${ }^{[32]}$ 。此外, 应结合类群特性和实际情况, 在分层抽样的基础上, 进一步搭配系统抽样等其他相关抽样方法 ${ }^{[7]}$ 。总体上, 抽样方案应该满足以下标准: 首先, 整体设计逻辑清晰, 方法科学实用, 易被不同人群所理解接受, 具有可操作 性, 划定明确且有代表性的抽样区, 能真实反映保护优先区生物多样性现状; 其次, 突出数据的可对比性, 调查 结果要满足后续评估需要, 可揭示有意义的保护和管理成效; 最后, 强调抽样效率, 应充分利用和整合现有科 考成果, 考虑人力、经费等实际限制条件, 抽样强度合理现实, 保证抽样结果是能完成的。项目执行过程中应 
对本区域的抽样方案进行评估, 向项目管理组报告在实际工作中发现的问题,进一步完善抽样设计,最终形成 一套保护优先区标准化抽样方案。

项目顶层设计和管理是保护优先区生物多样性调查评估的重要环节 ${ }^{[30-33]}$, 需结合项目目标和预期成果, 明确调查区域,提出具有指示意义的、科学可行的分析框架,同时应重视累积的基础数据的深人讨论,为揭示 管理措施与保护成效之间的关系提供有力支撑。目前,随着生物多样性保护重大工程的全面开展,保护优先 区区域尺度的抽样方案是一个亟需解决的科学问题。本研究提出的抽样策略进一步完善了保护优先区生物 多样性基础调查系统, 强化了项目管理能力, 能为未来其他保护优先区调查评估项目的开展提供一定的科学 参考与借鉴。

\section{2 结论}

生物多样性是人类赖以生存和发展的基础,关乎全球生命共同体,关系人类福祉,也是衡量一个国家和民 族文明程度的重要标志, 而生物多样性保护优先区是我国为加强生物多样性保护和监管划定的关键区域。抽 样方案设计是获取生物多样性有效调查数据的关键环节,本文以武陵山生物多样性保护优先区为例, 基于层 次聚类和系统抽样方法, 综合考虑历史调查资料的系统完整程度和空间保护属性, 提出了一个科学可行的区 域尺度的抽样方案。武陵山区范围内的县域可以分为 5 类,每类挑选出 2 个重点县域,包括 6 个历史上进行 过系统科学考察的县域和 4 个本底资料相对缺乏的县域,最终进一步获得 76 个代表性重点调查网格,其中生 物多样性富集网格 36 个,保护区外的人类干扰网格 40 个,抽样比例为 $11.09 \%$,每个网格平均调查经费为 2.52 万元。该抽样策略解决了保护优先区区域尺度的抽样问题,进一步完善了生物多样性基础调查系统, 能 为未来其他保护优先区项目开展提供一定的科学参考与借鉴。

\section{参考文献 (References) :}

[ 1 ] 蒋志刚. 中国脊椎动物生存现状研究. 生物多样性, 2016, 24(5) : 495-499.

[ 2 ] The Biodiversity Committee of Chinese Academy of Sciences. Catalogue of life China 2020 annual checklist. [2020- 10-20]. http://www.sp2000. org.cn.

[ 3 ] 柏成寿, 崔鹏. 我国生物多样性保护现状与发展方向. 环境保护, 2015, 43(5)：17-20.

[ 4 ] 王艳杰, 武建勇, 赵富伟, 薛达元. 全球生物剽窃案例分析与中国应对措施. 生态与农村环境学报, 2014, 30(2): 146-154.

[ 5 ] 薛达元. 《中国生物多样性保护战略与行动计划》的核心内容与实施战略. 生物多样性, 2011, 19(4): 387-388.

[ 6 ] 徐海根, 丁目军, 吴军, 曹铭昌, 陈炼, 乐志芳, 崔鹏. 2020 年全球生物多样性目标解读及其评估指标探讨. 生态与农村环境学报, 2012 , 28(1): $1-9$.

[ 7 ] 徐海根, 丁晖, 吴军, 曹铭昌, 崔鹏, 陈炼, 雷军成, 乐志芳, 吴翼. 生物物种资源监测原则与指标及抽样设计方法. 生态学报, 2013, 33 (7) : 2013-2022.

[ 8 ] Balmford A, Green R E, Jenkins M. Measuring the changing state of nature. Trends in Ecology \& Evolution, 2003, 18(7) : 326-330.

[ 9 ] Henry P Y, Lengyel S, Nowicki P, Julliard R, Clobert J, Čelik T, Gruber B, Schmeller D S, Babij V, Henle K. Integrating ongoing biodiversity monitoring: potential benefits and methods. Biodiversity and Conservation, 2008, 17( 14) : 3357-3382.

[10] 宋大祥. 西南武陵山地区动物资源和评价. 北京: 科学出版社, 1994: 1-431.

[11] 王文采. 武陵山地区维管植物检索表. 北京: 科学出版社, 1995: 1-626.

[12] 黄复生. 西南武陵山地区昆虫. 北京: 科学出版社, 1993: 1-738.

[13] 宋大祥. 西南武陵山地区无脊椎动物. 北京: 科学出版社, 1997: 1-523.

[14] Myers N, Mittermeier R A, Mittermeier C G, da Fonseca G A B, Kent J. Biodiversity hotspots for conservation priorities. Nature, 2000, 403 (6772) : 853-858.

[15] 祁承经, 喻勋林, 曹铁如, 周建仁. 湖南八大公山的植物区系及其在植物地理学上的意义. 云南植物研究, 1994, 16(4) : 321-332.

[16] Jenkins C N, Pimm S L, Joppa N L. Global patterns of terrestrial vertebrate diversity and conservation. Proceedings of the National Academy of Sciences of the United States of America, 2013, 110(28) : E2602-E2610.

[17] Roll U, Feldman A, Novosolov M, Allison A, Bauer A M, Bernard R, Böhm M, Castro-Herrera F, Chirio L, Collen B, Colli G R, Dabool L, Das I, Doan T M, Grismer L L, Hoogmoed M, Itescu Y, Kraus F, LeBreton M, Lewin A, Martins M, Maza E, Meirte D, Nagy Z T, de C. Nogueira C, Pauwels O S G, Pincheira-Donoso D, Powney G D, Sindaco R, Tallowin O, Torres-Carvajal O, Trape J F, Vidan E, Uetz P, 
Wagner P, Wang Y Z, Orme C D L, Grenyer R, Meiri S. Author Correction: the global distribution of tetrapods reveals a need for targeted reptile conservation. Nature Ecology \& Evolution, 2018, 2(1): 193.

[ 18] Xu H G, Cao M C, Wu Y, Cai L, Cao Y, Wu J, Lei J C, Le Z F, Ding H, Cui P. Disentangling the determinants of species richness of vascular plants and mammals from national to regional scales. Scientific Reports, 2016, 6: 21988.

[19] 侯学显. 中国植被图集: 1: 1000000. 北京: 科学出版社, 2001: 101-104.

[20] Su Y J, Guo Q H, Hu T Y, Guan H C, Jin S C, An S Z, Chen X L, Guo K, Hao Z Q, Hu Y M, Huang Y M, Jiang M X, Li J X, Li Z J, Li X K, Li X W, Liang C Z, Liu R L, Liu Q, Ni H W, Peng S L, Shen Z H, Tang Z Y, Tian X J, Wang X H, Wang R Q, Xie Z Q, Xie Y Z, Xu X N, Yang X B, Yang Y C, Yu L F, Yue M, Zhang F, Ma K P. An updated vegetation map of China (1:1000000). Science Bulletin, 2020, 65 (13) : 1125-1136.

[21] Venter O, Sanderson E W, Magrach A, Allan J R, Beher J, Jones K R, Possingham H P, Laurance W F, Wood P, Fekete B M, Levy M A, Watson J E M. Global terrestrial Human Footprint maps for 1993 and 2009. Scientific Data, 2016, 3: 160067.

[22] 孙吉贵, 刘杰, 赵连宇. 聚类算法研究. 软件学报, 2008, 19(1) : 48-61.

[23] 段明秀. 层次聚类算法的研究及应用 $[\mathrm{D}]$. 长沙: 中南大学, 2009.

[24］吴夙慧，成颖，郑彦宁，潘云涛. K-means 算法研究综述. 现代图书情报技术, 2011, 205(05) : 28-35.

[25] Johnson S C. Hierarchical clustering schemes. Psychometrika, 1967, 32(3) : 241-254.

[26] Buckland W R. A review of the literature of systematic sampling. Journal of the Royal Statistical Society. Series B, 1951, 13(2) : 208-215.

[27] Etikan I, Bala K. Sampling and sampling methods. Biometrics \& Biostatistics International Journal, 2017, 5(6) : 215-217.

[28] Xu H G, Wu J, Liu Y, Ding H, Zhang M, Wu Y, Xi Q, Wang L L. Biodiversity congruence and conservation strategies: a national test. BioScience, 2008, 58(7): 632-639.

[29] Yoccoz N G, Nichols J D, Boulinier T. Monitoring of biological diversity in space and time. Trends in Ecology \& Evolution, 2001, 16(8): 446- 453 .

[30] 武建勇, 薛达元, 王爱华, 赵富伟. 生物多样性重要区域识别——国外案例、国内研究进展. 生态学报, 2016, 36(10): 3108-3114.

[31] 陈佐忠, 汪诗平. 草地生态系统观测方法. 北京: 中国环境科学出版社, 2004: 75-142.

[ 32] Green R E, Balmford A, Crane P R, Mace G M, Reynolds J D, Turner R K. A framework for improved monitoring of biodiversity: responses to the world summit on sustainable development. Conservation Biology, 2005, 19(1) : 56-65.

[33] 王秀琴, 陈传忠, 赵岑. 关于加强环境监测顶层设计的思考. 中国环境监测, 2014, 30(1) : 187- 190 . 